MEI, II, Vol. 3, nº 4, pág. 127

MEI

II, vol. 3

$\mathrm{n}^{0} 4$

\title{
Las normas técnicas de interoperabilidad relativas al documento electrónico
}

\author{
Miguel A. Amutio Gómez \\ Ministerio de Política Territorial y Administración Pública
}

\section{Resumen}

Las administraciones públicas españolas vienen realizando un esfuerzo considerable en los últimos años para garantizar a los ciudadanos su derecho a relacionarse electrónicamente con ellas. La seguridad jurídica, aspecto esencial en la implantación de la administración electrónica, ha absorbido parte de ese esfuerzo, orientado al desarrollo de la Ley 11/2007 y materializado en el Real Decreto 1671/2009 de desarrollo parcial de la Ley 11/2007, y seguidamente, en los Reales Decretos 3/2010 y 4/2010 relativos a los esquemas nacionales de seguridad e interoperabilidad respectivamente, que desarrollan los principios y pautas necesarios para crear condiciones de confianza en los sistemas tecnológicos y para la cooperación entre las distintas administraciones.

En julio de 2011, se han publicado siete de las normas técnicas de interoperabilidad de la serie prevista en el Real Decreto 4/2010. En este texto se exponen los aspectos principales de las normas técnicas de interoperabilidad relativas al documento electrónico, la metodología seguida para su elaboración, así como el contexto de colaboración en el que se han producido.

\section{Palabras clave}

Interoperabilidad, Documento electrónico, Expediente electrónico, Digitalización de documentos.

The technical standards for interoperability relating to electronic document

Abstract

The Spanish government are making a considerable effort in recent years to guarantee citizens their right to interact electronically with them. Legal security, essential in the implementation of e-government, has taken part of that effort, aimed at the development of Law 11/2007 and materialized in RD 1671/2009 partial development of Law $11 / 2007$, and then, in the RD 3/2010 and 4/2010 concerning national security schemes and interoperability respectively, which develop the principles and guidelines needed to create an environment of trust in technology systems and cooperation between the various authorities.

In July 2011, they have released seven of the technical standards for interoperability of the series pursuant to $\mathrm{RD}$ 4/2010. This text presents the main aspects of technical standards for interoperability relating to the electronic document, the methodology for their development as well as the collaborative context in which they occurred.

\section{Keywords}

Interoperability, Electronic document, Electronic record, Digitization of documents.

\section{Normas Técnicas de Interoperabilidad}

Las Normas Técnicas de Interoperabilidad, previstas en la disposición adicional primera del Real Decreto 4/2010, de 8 de enero, por el que se regula el Esquema Nacional de Interoperabilidad en el ámbito de la Administración Electrónica, desarrollan una colección de aspectos técnicos sobre los cuales 
se consideró necesario establecer unas condiciones concretas, específicas, con un nivel de detalle y extensión y, en algunos casos, con unos requisitos de actualización periódica tales que no era posible, ni adecuado, establecerlos en el propio Real Decreto 4/2010. Vienen, por tanto, a concretar detalles para facilitar los aspectos más prácticos y operativos de la interoperabilidad entre las Administraciones públicas y con el ciudadano. Por otra parte, la estructura de las resoluciones de aprobación de las normas se ciñe a la práctica habitual para el tratamiento de cuestiones técnicas aplicada también en otros sectores, como es el caso, por ejemplo, de los sectores de telecomunicaciones, edificación u obra civil.

Estas normas constituyen un hito importante en el desarrollo del Esquema Nacional de Interoperabilidad, establecido en el apartado 1 del artículo 42 de la Ley 11/2007, de 22 de junio, de acceso electrónico de los ciudadanos a los Servicios Públicos y regulado por el citado Real Decreto 4/2010. Recuérdese que este Esquema tiene por objeto comprender el conjunto de criterios y recomendaciones que deberán ser tenidos en cuenta por las Administraciones públicas para la toma de decisiones tecnológicas que garanticen la interoperabilidad; y que su finalidad es la creación de las condiciones necesarias para garantizar el adecuado nivel de interoperabilidad técnica, semántica y organizativa de los sistemas y aplicaciones empleados por las Administraciones públicas, que permitan el ejercicio de derechos y el cumplimiento de deberes a través del acceso electrónico a los servicios públicos, a la vez que una mejora notable de la eficacia y la eficiencia.

El 30 de julio de 2011 se publicaron en el Boletín Oficial del Estado siete de las Normas Técnicas de Interoperabilidad; en particular, las referidas a documento electrónico, expediente electrónico, digitalización de documentos, procedimientos de copiado auténtico y conversión entre documentos electrónicos, política de firma electrónica y de certificados de la Administración, requisitos de conexión a la Red de comunicaciones de las Administraciones públicas españolas y modelo de datos para el intercambio de asientos entre Entidades Registrales. A la fecha de redacción de este texto se encuentran en elaboración las normas correspondientes a Catálogo de estándares, Relación de modelos de datos, Protocolos de intermediación, Política de gestión de documentos electrónicos y Declaración de conformidad con el Esquema Nacional de Interoperabilidad.

Dentro del conjunto de Normas Técnicas de Interoperabilidad, las normas de Documento electrónico, Expediente electrónico, Digitalización de documentos, Procedimientos de copiado auténtico y conversión entre documentos electrónicos y de Política de gestión de documentos electrónicos responden a lo previsto en el artículo 21 del Real Decreto 4/2010, sobre interoperabilidad, recuperación y conservación del documento electrónico, a la luz de la necesidad de garantizar todos estos aspectos para el documento electrónico a lo largo del tiempo. Adicionalmente, hay otras normas que resultan de interés para el documento electrónico como son las de Política de firma electrónica y de certificados de la Administración y de Catálogo de estándares.

El ámbito de aplicación de estas normas es el establecido en el artículo 3 del Real Decreto 4/2010 y se centra esencialmente en los documentos administrativos electrónicos y en otros documentos electrónicos susceptibles de formar parte de un 
expediente electrónico. Esta distinción entre 'documento administrativo electrónico' y 'documento electrónico' tiene su explicación en el artículo 29 de la Ley 11/2007 en el que se establecen las condiciones para la emisión válida de documentos administrativos por medios electrónicos por parte de las Administraciones públicas, de manera que no se dispone de una definición como tal de documento administrativo electrónico sino que se formulan unos requisitos adicionales relativos a la incorporación de una o varias firmas electrónicas y de la referencia temporal.

A continuación se exponen los aspectos principales de las normas técnicas de interoperabilidad relativas al documento electrónico, la metodología seguida para su elaboración, así como el contexto de colaboración en el que se han producido.

\section{Documento electrónico}

La Norma Técnica de Interoperabilidad de Documento Electrónico establece las condiciones técnicas mínimas necesarias para permitir un intercambio de documentos electrónicos normalizado, para lo cual establece los componentes del documento y la estructura para su intercambio, dado que son las cuestiones clave para la interoperabilidad de los mismos. Quedan, por tanto, fuera del objeto de la norma cuestiones tales como establecer una implantación específica del documento electrónico más allá de operaciones de intercambio y comunicación; o establecer un procedimiento de gestión y conservación del documento electrónico.

La diversidad tanto de las Administraciones públicas como de sus circunstancias se manifiesta en relación con el documento electrónico en que mientras que para algunas la principal necesidad es el manejo e intercambio de grandes volúmenes de documentos, para otras el punto clave de su problemática es garantizar su conservación a largo plazo. En cualquier caso, la necesidad de establecer ciertas pautas para la normalización de los intercambios de documentos electrónicos es asumida y bien conocida y constituye una pieza clave para la interoperabilidad en un contexto en el que el objeto de intercambio es el documento electrónico y no solamente los datos que aquél porta. Además, se ha concebido respetando y para respetar posibles ámbitos particulares de interés, como así han entendido los actores involucrados en su elaboración.

La Ley 11/2007 define el documento electrónico como “información de cualquier naturaleza en forma electrónica, archivada en un soporte electrónico según un formato determinado y susceptible de identificación y tratamiento diferenciado" y especifica, en su artículo 29, particularidades de la emisión de documentos administrativos por medios electrónicos. Además, el Real Decreto 1671/2009 especifica a lo largo de su Título VI (artículo 41 y $\quad$ ss.), disposiciones comunes sobre documentos electrónicos, consideraciones específicas para documentos administrativos electrónicos así como sobre el archivo y conservación de documentos electrónicos. La Norma Técnica de Interoperabilidad de Documento Electrónico parte de lo anterior para concretar los aspectos más estrechamente relacionados con el intercambio de documentos electrónicos.

En primer lugar se establecen los componentes del documento electrónico: el contenido; en su caso, la firma electrónica; y los metadatos del documento electrónico. 
En cuanto al contenido, entendido como el conjunto de datos o información de cualquier naturaleza que es objeto del propio documento electrónico, con el fin de facilitar la interoperabilidad y la gestión de los intercambios, la norma contempla el intercambio de documentos electrónicos simples, entendiendo éstos como aquellos que solamente incluyen un fichero de información o contenido, una o varias firmas, si procede, y un conjunto de metadatos asociados. Esta consideración sobre lo que se ha llamado 'documentos electrónicos simples', si bien no tiene una mención explícita en los apartados de la norma, se impone en la estructura XML para el intercambio de documentos electrónicos que incluye su anexo II.

En cuanto a la firma electrónica de los documentos administrativos electrónicos y, en su caso, de aquellos otros susceptibles de formar parte de un expediente, ésta responderá a lo establecido en la normativa aplicable a tal efecto, ya que, el artículo 13 y siguientes de la Ley 11/2007 y los artículos 18 al 20 del Real Decreto 4/2010 detallan las condiciones de uso de la firma electrónica en el ámbito objeto de la norma. En este sentido, obsérvese que la norma contempla la utilización de las firmas electrónicas señaladas en la Decisión de la Comisión 2011/130/EU1', cuestión también recogida en la Norma Técnica de Interoperabilidad de Política de firma electrónica y de certificados de la Administración.

En cuanto a los metadatos, como información de contexto que permite la localización y tratamiento diferenciado de los documentos electrónicos, la norma establece el conjunto de metadatos mínimos obligatorios del documento electrónico, que se definen en el anexo I, y que, entendidos como información mínima de contexto para un tratamiento automatizado del documento, estarán presentes en cualquier proceso de intercambio.

Respecto a los metadatos complementarios, entendidos como información de contexto para atender a necesidades de descripción específicas que estarán contempladas en la gestión interna de documentos electrónicos de cada organización, lo previsto se limita a enmarcar su aplicación en la Norma Técnica de Interoperabilidad de Política de gestión de documentos electrónicos; y a establecer la obligación en cuanto a garantizar la disponibilidad e integridad de los metadatos de los documentos electrónicos.

Por otra parte, no se hacen previsiones con respecto a la forma de implementación a nivel interno de los metadatos que forman parte de un documento electrónico (incrustación, vinculación, etc.); a este respecto, la implementación de metadatos por parte de cada administración es libre, siempre y cuando se cumpla el requisito mínimo necesario de mantener de manera permanente las relaciones entre el documento y sus metadatos; tampoco se hace ninguna previsión sobre la firma de los metadatos.

En cuanto al formato del documento electrónico:

- Se apunta a la Norma Técnica de Interoperabilidad de Catálogo de estándares, en elaboración a la fecha, ya que será ésta la que incluya el detalle de los estándares y, por tanto, de los formatos aplicables al fichero de contenido de un documento electrónico.

- Se establece que la selección del formato debe ser conforme a la naturaleza de 
la información con el fin de favorecer el acceso a aquella por parte de los interesados.

- Además, con el objetivo de dar cobertura a especiales circunstancias en que la Administración se ve obligada a asumir la carga de la prueba, como puede suceder en relación con la incautación de documentos en procesos de inspección fiscal, se reconoce la posibilidad de que la Administración conserve documentos electrónicos en otros formatos, en aras de conservar su valor probatorio.

En relación con las condiciones básicas para el intercambio de documentos electrónicos, con el objetivo de proporcionar un marco normalizado la norma establece lo siguiente:

- La obligatoriedad de intercambiar todos los componentes del documento.

- El uso de la estructura normalizada que se incluye como anexo II de la norma para el intercambio de documentos electrónicos. Se trata del código del esquema XML que integra los componentes del documento electrónico bajo una estructura normalizada y que permite también la aplicación de otras estructuras con normativa específica, como es el caso de la factura electrónica regulada mediante la ORDEN $P R E / 2971 / 2007^{2}$.

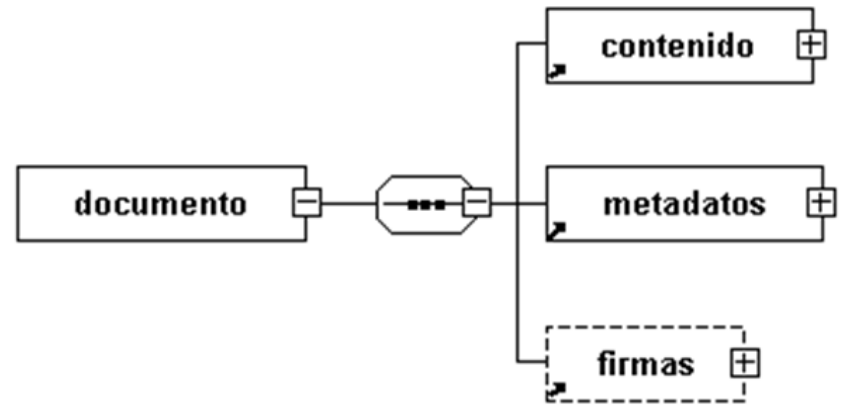

Figura 1: XSD de Documento electrónico

- La excepcionalidad en la aplicación de otras estructuras de intercambio que podrían ser utilizadas en caso de acuerdo previo entre las partes que, en caso de ser reenviadas a un tercero, deberían adaptarse a la estructura del anexo II por el emisor de dicho intercambio posterior.

- La utilización preferente de la Red de comunicaciones de las Administraciones Públicas españolas, prestada por la Red SARA, según las condiciones previstas en la Norma Técnica de Interoperabilidad correspondiente, como medio para la transmisión de acuerdo con lo establecido en el artículo 43 de la Ley 11/2007 y en el 13 del Real Decreto 4/2010.

- Si el documento electrónico forma parte de un asiento registral, su 
tratamiento como documento adjunto al mensaje de datos de intercambio según lo establecido en la Norma Técnica de Interoperabilidad de Modelo de Datos para el intercambio de asientos entre las Entidades Registrales que incluye la especificación completa de dicho modelo.

Además, con el fin de garantizar las condiciones necesarias para la conservación permanente, en caso de intercambios que responden a transferencia de custodia o traspaso de responsabilidad de gestión de documentos que deban conservarse permanentemente, se establece que la verificación de la autenticidad e integridad de un documento electrónico se llevará a cabo bajo la responsabilidad del órgano o entidad transferidora en el momento en que ésta se produzca. Tras dicha transferencia, el nuevo responsable de la custodia será el encargado de la conservación de la autenticidad e integridad del documento electrónico.

Por último, el apartado sobre acceso a documentos electrónicos desarrolla los aspectos técnicos para garantizar el ejercicio del derecho del ciudadano a acceder a los documentos electrónicos, reconocido en el artículo 6 de la Ley 11/2007. Para ello, detalla la información, tanto de contenido, como de firma electrónica y metadatos, que debe facilitarse en el acceso a un documento electrónico.

\section{Expediente electrónico}

La Norma Técnica de Interoperabilidad de Expediente Electrónico establece la estructura y formato del expediente electrónico para su intercambio, así como las especificaciones de los servicios de remisión y puesta a disposición de los expedientes electrónicos. Además, como buena práctica de gestión documental, la norma refleja la posibilidad de aplicar lo establecido para expedientes electrónicos a otros conjuntos de documentos electrónicos formados mediante agregación que creados al margen de un procedimiento reglado son fruto de una secuencia de actuaciones coherentes.

La necesidad de establecer ciertas pautas para la normalización de los servicios de remisión y puesta a disposición de expedientes electrónicos es asumida y bien conocida por todas las Administraciones Públicas y se aborda en la norma concretando la implementación del índice electrónico que, como elemento para garantizar la integridad y recuperación del expediente, constituye una pieza clave en la implantación del expediente electrónico y su interoperabilidad.

Quedan fuera del objeto de la norma cuestiones tales como establecer una implantación específica del expediente electrónico más allá de operaciones de intercambio y comunicación, de manera que la norma no hace previsiones con respecto a la forma de implementación a nivel interno de los diferentes componentes de un expediente electrónico (índice, documentos y metadatos) fuera de operaciones de intercambio; o establecer un procedimiento de gestión del expediente electrónico y de su conservación.

La Ley 11/2007 define el expediente electrónico como "conjunto de documentos electrónicos correspondientes a un procedimiento administrativo, cualquiera que sea el tipo de información que contengan”; especifica que el foliado se realiza a través de 
un índice electrónico definido a su vez como "relación de documentos electrónicos de un expediente electrónico, firmada por la Administración, órgano o entidad actuante, según proceda y cuya finalidad es garantizar la integridad del expediente electrónico y permitir su recuperación siempre que sea preciso"; y equipara, a efectos legales, la remisión del expediente con su puesta a disposición teniendo el interesado derecho a obtener copia del mismo. Además, el Real Decreto 1671/2009 especifica en su artículo 53 consideraciones específicas para la formación de los expedientes electrónicos, así como las reglas a seguir para su intercambio. En consecuencia, la norma parte de lo anterior para concretar los aspectos más relacionados con la formación y los servicios de remisión y puesta a disposición del expediente electrónico.

En primer lugar, tras el objeto y el ámbito de aplicación se establecen los componentes del expediente electrónico:

- Los documentos electrónicos para los que, como tales, es de aplicación lo establecido en la Norma Técnica de Interoperabilidad de Documento Electrónico sobre estructura y formato. Para facilitar diversas circunstancias de manipulación e intercambio de los expedientes, la norma incluye la posibilidad de incluirlos, bien como elementos independientes, bien dentro de una carpeta, entendida ésta como una agrupación de documentos electrónicos creada por un motivo funcional, o bien como parte de otro expediente, anidado en el primero.

- El índice electrónico atiende a lo establecido en el artículo 32.2 de la Ley $11 / 2007$, responde a lo declarado en el apartado b) del artículo 21 del Real Decreto 4/2010. Se detalla que recogerá el conjunto de documentos electrónicos asociados al expediente en un momento dado, con el fin de reflejar la evolución del mismo, y, si es el caso, la disposición en carpetas o expedientes de los documentos electrónicos que forman el expediente. Obsérvese que la norma no establece ninguna consideración relativa al tratamiento del índice electrónico como documento electrónico o como otro tipo de objeto digital a nivel interno de cada organización, sino que se limita a reflejar sus características funcionales y sólo establece una implementación concreta de cara al intercambio del expediente.

- La firma electrónica del índice electrónico, que no del expediente electrónico, como mecanismo de garantía de la integridad del expediente y que aplicará lo ya establecido en los artículos 18 y 19 de la Ley 11/2007 en cuanto a la firma por parte de la Administración pública correspondiente. Obsérvese que, al igual que en el caso de la norma de Documento electrónico, se contempla la utilización de las firmas electrónicas señaladas en la antes citada Decisión de la Comisión 2011/130/EU. 


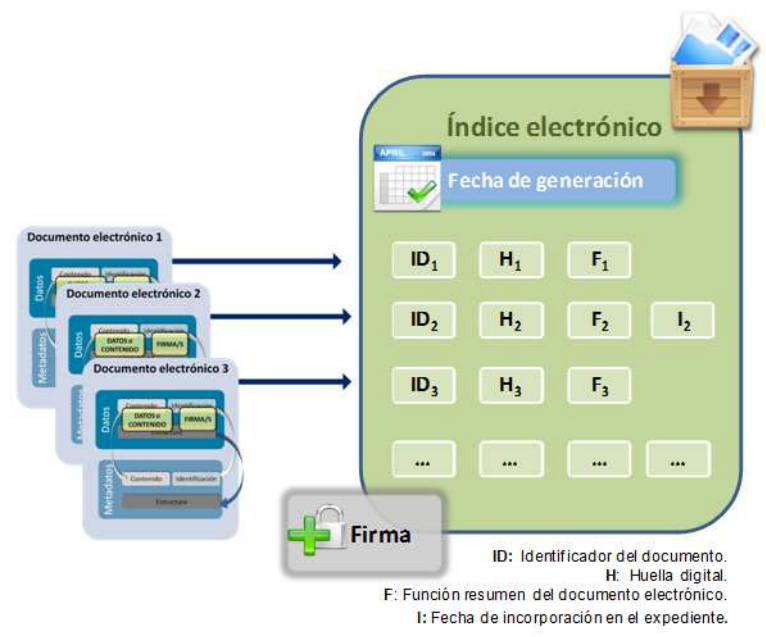

Figura 2: Ejemplo básico del índice electrónico

- Metadatos del expediente electrónico, como información de contexto que, al igual que para los documentos electrónicos, constituye una herramienta para facilitar su gestión, recuperación y tratamiento diferenciado. Se establece el conjunto de metadatos mínimos obligatorios del expediente electrónico, definidos en el anexo I, y que, entendidos como información mínima de contex to para un tratamiento automatizado del expediente, estarán presentes en cualquier servicio de remisión o puesta a disposición, en aras de potenciar su interoperabilidad. Asimismo, se da cabida a la posibilidad de asignar otros metadatos complementarios, como respuesta a necesidades de descripción específicas que estarán enmarcadas en la gestión interna de expedientes electrónicos de cada organización, por lo que se contemplan en la aplicación de una política de gestión conforme a la Norma Técnica de Interoperabilidad de Política de gestión de documentos electrónicos. 
MEI, II, Vol. 3, n 4, pág. 135

\begin{tabular}{|c|c|c|c|c|}
\hline Metadato & $\begin{array}{l}\text { Descripción / } \\
\text { Condiciones de uso }\end{array}$ & ¿Repetible? & Tipo & Esquema de valores \\
\hline Versión NTI & \begin{tabular}{|l|} 
Identificador \\
normalizado de la \\
versión de la Norma \\
Técnica de \\
Interoperabilidad de \\
Expediente electrónico \\
conforme a la cual se \\
estructura el \\
expediente.
\end{tabular} & 1 & URI & $\begin{array}{l}\text { http://administracionelectronica.gob.es/ENI/X } \\
\text { SD/v1.0/expediente-e }\end{array}$ \\
\hline Identificador & $\begin{array}{l}\text { Identificador } \\
\text { normalizado del } \\
\text { expediente. }\end{array}$ & 1 & $\begin{array}{l}\text { Cadena de } \\
\text { caracteres }\end{array}$ & 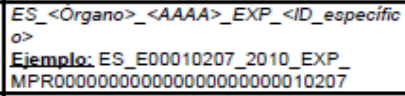 \\
\hline Órgano & \begin{tabular}{|l|} 
Identificador \\
normalizado de la \\
administración \\
responsable de la \\
tramitación del \\
procedimiento \\
\end{tabular} & $1: \mathrm{N}$ & $\begin{array}{l}\text { Cadena de } \\
\text { caracteres }\end{array}$ & $\begin{array}{l}\text { Código alfanumérico único para cada } \\
\text { órgano/unidad/oficina extraído del Directorio } \\
\text { Común gestionado por el Ministerio de } \\
\text { Política Territorial y Administración Pública. } \\
\text { Eiemplo: E00003901 } \\
\end{array}$ \\
\hline $\begin{array}{l}\text { FechaApertura } \\
\text { Expediente }\end{array}$ & $\begin{array}{l}\text { Fecha de apertura del } \\
\text { expediente }\end{array}$ & 1 & Fecha/hora & $\begin{array}{l}\text { Formato: AAAAMMDD T HH:MM:SS } \\
\text { <ISO 8601> }\end{array}$ \\
\hline Clasificación & $\begin{array}{l}\text { Procedimiento } \\
\text { administrativo con el } \\
\text { que se relaciona el } \\
\text { expediente. }\end{array}$ & 1 & $\begin{array}{l}\text { Cadena de } \\
\text { caracteres }\end{array}$ & $\begin{array}{l}\text { Esquema de valores normalizado según el } \\
\text { Sistema de Información Administrativa (SIA). } \\
\text { Si el procedimiento no se encuentra en SIA: } \\
\langle\text { Órgano>PRO_LID_PRO_especifico> }\end{array}$ \\
\hline Estado & $\begin{array}{l}\text { Estado del expediente } \\
\text { en el momento de } \\
\text { intercambio. }\end{array}$ & 1 & $\begin{array}{l}\text { Cadena de } \\
\text { caracteres }\end{array}$ & $\begin{array}{ll} & \text { Abierto } \\
- & \text { Cerrado } \\
- & \text { índice para remisión cerrado. } \\
\end{array}$ \\
\hline Interesado & $\begin{array}{l}\text { Identificador del } \\
\text { interesado. }\end{array}$ & $0: \mathrm{N}$ & $\begin{array}{l}\text { Cadena de } \\
\text { caracteres }\end{array}$ & $\begin{array}{l}\text { a) Si ciudadano o persona jurídica: DNI, NIE, } \\
\text { NIF o similar. } \\
\text { b) Si administración: <Órgano> }\end{array}$ \\
\hline Tipo de firma & $\begin{array}{l}\text { Indica el tipo de firma } \\
\text { del indice del } \\
\text { expediente. }\end{array}$ & $1: \mathrm{N}$ & $\begin{array}{l}\text { Cadena de } \\
\text { caracteres }\end{array}$ & $\begin{array}{l}\text { - 'CSV' } \\
\text { - Formatos de firma electrónica de } \\
\text { documentos electrónicos definidos en la } \\
\text { Norma Técnica de Interoperabilidad de } \\
\text { Política de firma y certificados de la } \\
\text { Administración. }\end{array}$ \\
\hline \multicolumn{5}{|c|}{ Si "Tipo de firma" = CSV } \\
\hline Valor CSV & Valor del CSV. & $1: \mathrm{N}$ & $\begin{array}{l}\text { Cadena de } \\
\text { caracteres }\end{array}$ & N/A \\
\hline $\begin{array}{l}\text { Definición } \\
\text { generación CSV }\end{array}$ & $\begin{array}{l}\text { Referencia a la Orden, } \\
\text { Resolución o } \\
\text { documento que define } \\
\text { la creación del CSV } \\
\text { correspondiente. }\end{array}$ & $1: \mathrm{N}$ & $\begin{array}{l}\text { Cadena de } \\
\text { caracteres }\end{array}$ & $\begin{array}{l}\text { Si AGE: } \\
\text { Referencia BOE:BOE-A-YYYY-Xxxxx } \\
\text { En otro caso, referencia correspondiente. }\end{array}$ \\
\hline
\end{tabular}

Figura 3: Tabla de metadatos del expediente electrónico.

Seguidamente se establecen las condiciones básicas para el intercambio de expedientes electrónicos con el objetivo de proporcionar un marco normalizado:

- El uso de la estructura normalizada, que se incluye como anexo II de la norma, para el intercambio de expedientes electrónicos; se trata del código del esquema XML que integra los componentes del expediente electrónico bajo una estructura normalizada. Además, para su intercambio, se establece que se remitirá, en primer lugar, la estructura de aplicación al expediente, seguida de los documentos electrónicos que lo componen, que adoptarán la estructura de intercambio que corresponda atendiendo a la Norma Técnica de Interoperabilidad de Documento Electrónico, y se enviarán en el orden indicado en el índice. 


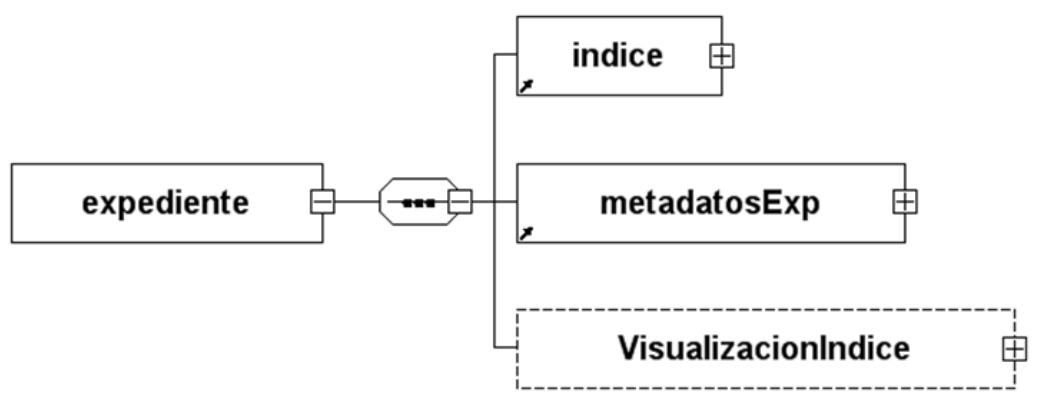

Figura 4: XSD de expediente electrónico.

- La excepcionalidad en la aplicación de otras estructuras de intercambio que podrían ser utilizadas en caso de acuerdo previo entre las partes que, en caso de ser reenviadas a un tercero, deberían adaptarse a la estructura del anexo II por el emisor de dicho intercambio posterior.

- La posibilidad de que documentos cuya naturaleza o extensión no permiten o dificultan notablemente su inclusión en la estructura establecida se reflejen en el expediente intercambiado a través de un documento en el que se especifica cuáles son. Este punto atiende a lo dispuesto en el apartado 2.d) del artículo 53 del Real Decreto 1671/2009 y da cobertura a la inclusión en el expediente electrónico de otro tipo de documentos cuya conversión pueda suponer una pérdida de valor probatorio, que, en cualquier caso serán custodiados por el órgano gestor sin perjuicio de aportación separada cuando así se requiera.

- El contenido del índice electrónico de los expedientes objeto de intercambio definido en la norma refleja y desarrolla lo establecido en el apartado 2 del artículo 53 del Real Decreto 1671/2009. Según esto, el índice electrónico a intercambiar está formado por la fecha de generación del mismo, la identificación y una huella digital de cada documento y, además, si es el caso, el índice reflejaría la disposición de los documentos en carpetas y expedientes electrónicos anidados.

Finalmente, al igual que en el caso del documento electrónico, con el fin de garantizar las condiciones necesarias para la conservación permanente, en caso de intercambios que responden a transferencia de custodia o traspaso de responsabilidad de gestión de expedientes que deban conservarse permanentemente, se establece que la verificación de la autenticidad e integridad de un expediente electrónico se llevará a cabo bajo la responsabilidad del órgano o entidad transferidora en el momento en que ésta se produzca. Tras dicha transferencia, el nuevo responsable de la custodia será el encargado de la conservación de la autenticidad e integridad del expediente electrónico. 
Obsérvese que en la estructura XML para el intercambio de expedientes, el índice no constituye un documento electrónico en tanto que no tiene metadatos mínimos obligatorios asociados; por tanto, es responsabilidad de cada organización el diseño e implementación del índice de sus expedientes bajo la fórmula que mejor se ajuste a sus necesidades y normativa específica aplicable, con la única restricción de que permita la traslación de la información a la estructura XML indicada en la norma en caso de intercambio.

\section{Digitalización de documentos}

La Norma Técnica de Interoperabilidad de Digitalización de Documentos establece las reglas para la digitalización de documentos en soporte papel o en otro soporte no electrónico susceptible de digitalización a través de medios fotoeléctricos, partiendo de lo establecido al respecto en la Ley 11/2007 y en el Real Decreto 4/2010, para concretar los aspectos más relacionados con la digitalización de documentos, y teniendo presente también las condiciones establecidas en el Real Decreto 1671/2009. Estas reglas sientan unas bases mínimas para procesos de digitalización que pueden ser llevados a cabo, tanto de forma interna por las Administraciones Públicas como a través de un tercero y abarcar documentos puntuales o digitalizaciones masivas y que, dependiendo de la finalidad y naturaleza de los documentos a digitalizar, pueden requerir de condiciones específicas.

Para ello estas bases mínimas se refieren a los parámetros básicos de dichos procesos digitalización, de manera que se permita la flexibilidad necesaria para su aplicación por parte de las diferentes Administraciones Públicas, pero siempre bajo la premisa de obtener imágenes electrónicas íntegras y fieles a su documento original. Se tratan, por tanto, sólo los requisitos mínimos de carácter técnico, siendo responsabilidad de cada organización la valoración de la necesidad de aplicar requisitos adicionales proporcionales a sus circunstancias específicas $\mathrm{y}$, en cualquier caso, a la normativa aplicable.

Otros soportes, como aquellos que registran sonido, vídeo o ambos, están excluidos del alcance de la norma, sin perjuicio de su posible inclusión en versiones posteriores. También quedan fuera del objeto cuestiones tales como describir el proceso de generación de copias electrónicas auténticas de documentos en soporte papel, definir un procedimiento formal concreto de digitalización, el tratamiento de imágenes electrónicas aportadas por los ciudadanos en sus relaciones con las administraciones, describir un procedimiento con carácter retroactivo para el tratamiento de documentos que hayan sido digitalizados con anterioridad a la publicación de la norma, constituir un instrumento para la homologación de aplicaciones o dispositivos de digitalización, sin perjuicio de que posibles futuras versiones se desarrollen considerando también dicha finalidad. También se evita la referencia a la destrucción de documentos originales para evitar que se pueda llegar a interpretar erróneamente que la digitalización puede suponer, por sí misma, la destrucción e los documentos originales.

El Real Decreto 4/2010 define la digitalización como "el proceso tecnológico que permite convertir un documento en soporte papel o en soporte no electrónico en uno o varios ficheros electrónicos que contienen la imagen codificada, fiel e integra del 
documento", y dedica el artículo 24 a la digitalización de documento en soporte papel. Además, el Real Decreto 1671/2009 en los artículos 44 y 46 establece consideraciones para la digitalización de documentos en soporte papel así como para su destrucción; obsérvese sin embargo que el artículo 48 del mismo Real Decreto referido a imágenes electrónicas aportadas por los ciudadanos no influye en el desarrollo de la norma técnica que se ciñe a la obtención de estas imágenes por parte de las Administraciones Públicas.

Tras el objeto y el ámbito de aplicación la norma establece los componentes de los documentos electrónicos digitalizados:

- Imagen electrónica, definida en el Real Decreto 4/2010 como el resultado de aplicar un proceso de digitalización a un documento y que, por tanto, ha de representar el aspecto y contenido del documento en el soporte origen.

- Como documento electrónico, son de aplicación los metadatos mínimos obligatorios definidos en la Norma Técnica de Interoperabilidad de Documento Electrónico.

- Dependiendo la naturaleza y finalidad del documento, firma de la imagen electrónica por parte de la administración que realiza la digitalización, mediante los sistemas de firma electrónica previstos en los artículos 18 ó 19 de la Ley $11 / 2007$.

Y se precisa que para la conformación de un documento electrónico digitalizado como copia auténtica debe aplicarse la Norma Técnica de Interoperabilidad de Procedimientos de copiado auténtico y conversión entre documentos electrónicos, ya que ésta define los requisitos para la obtención de copias electrónicas auténticas de documentos papel en respuesta a lo recogido en el artículo 30 de la Ley 11/2007 y el artículo 44 del Real Decreto $1671 / 2009$.

A continuación, el apartado relativo a los requisitos de la imagen electrónica trata lo siguiente:

- Apunta a la Norma Técnica de Interoperabilidad de Catálogo de estándares, ya que será ésta la que incluya el detalle de los estándares y, en concreto, de los formatos aplicables a la imagen electrónica del documento electrónico digitalizado.

- Establece el nivel de resolución mínimo en 200 píxeles por pulgada, tanto para imágenes obtenidas en blanco y negro, como en color o escala de grises, ya que esta resolución proporciona imágenes con detalle suficiente para mantener la fidelidad con el contenido original.

- Define pautas adicionales para conservar la fidelidad de la imagen electrónica resultante del proceso de digitalización con respecto al documento original, como las referidas a respetar la geometría del documento origen en tamaños y proporciones, evitar añadir caracteres o gráficos que no figurasen en el documento origen y aplicar un proceso de digitalización que reúna unas 
condiciones mínimas en cuanto a tareas y calidad.

La calidad del documento resultado del proceso de digitalización será determinada por la organización responsable del proceso, según las características o fines del producto de la digitalización y la normativa específica aplicable a cada caso. La noción de fidelidad de la imagen ha de interpretarse de forma proporcional a las exigencias de fidelidad e integridad específicas de cada documento en cada caso. En consecuencia, el modo en que, bajo cada circunstancia específica (legal, documental, social, técnica o cultural), se considere que un documento digital es fiel e íntegro, más allá de los mínimos establecidos por la norma, depende de las necesidades de cada organización, de su normativa específica, y, de ser necesario, de las condiciones que fuesen requeridas de manera específica en procesos judiciales.

Finalmente, el apartado relativo al propio proceso de digitalización define las tareas tipo a realizar:

- Digitalización del documento origen a través de un medio fotoeléctrico para la obtención de la imagen electrónica que, inicialmente, se registra en la memoria del sistema asociado al dispositivo.

- Optimización automática cuando la imagen obtenida lo requiera para garantizar su legibilidad, de modo que todo contenido del documento origen pueda apreciarse y sea válido para su gestión; esta optimización puede consistir en la aplicación de mecanismos de edición de imagen tales como la umbralización, reorientación o eliminación de bordes.

- Asignación de metadatos y, si procede, de firma electrónica con el fin de completar los componentes del documento electrónico digitalizado.

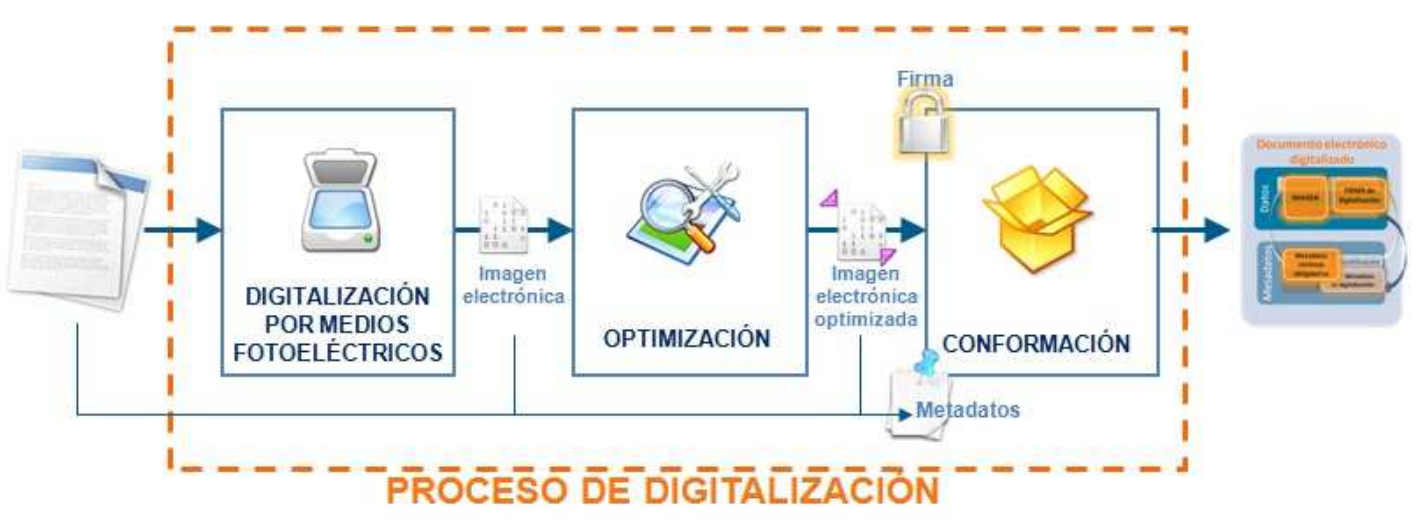

Figura 5: Proceso de digitalización 


\section{Procedimientos de copiado auténtico y conversión entre documentos electrónicos}

La Norma Técnica de Interoperabilidad de Procedimientos de copiado auténtico y conversión entre documentos electrónicos parte de lo establecido al respecto en el artículo 30 de la Ley 11/2007 para concretar las reglas relativas a la generación de copias electrónicas auténticas y a la conversión de formato de documentos electrónicos, teniendo también presente las condiciones establecidas en el Real Decreto 1671/2009, en sus artículos 43 y siguientes; todo ello sin perder de vista lo establecido en la normativa anterior, como el Real Decreto 772/19993.

Quedan fuera del objeto de la norma cuestiones tales como establecer una relación completa de requisitos y tipos de copias de documentos desde el punto de vista de su valor legal o jurídico, el tratamiento de copias electrónicas a efecto de compulsa, una definición de organizaciones y entes competentes para la generación de copias auténticas o una descripción de procedimientos de solicitud de copias, plazos de expedición y consideraciones específicas a aplicar según el contenido del documento sobre el que es necesario generar una copia (datos personales, datos de terceros, etc.). También se evita la referencia a la destrucción de documentos originales para evitar que se pueda llegar a interpretar erróneamente que la generación de una copia auténtica o la conversión entre documentos electrónicos pueden suponer, por sí mismas, la destrucción de los documentos originales.

Tras el objeto y el ámbito de aplicación, la norma señala en primer lugar las características generales de las copias electrónicas:

- Se recoge el reconocimiento de la eficacia jurídica de documento electrónico original a las copias electrónicas generadas que, por ser idénticas al documento electrónico original no comportan cambio de formato ni de contenido.

- Se definen las copias electrónicas auténticas como nuevos documentos electrónicos que incluyen total o parcialmente el contenido del documento sobre el que se expiden y que, como documentos electrónicos, han de cumplir con lo establecido en la Norma Técnica de Interoperabilidad de Documento Electrónico que desarrolla las condiciones para su intercambio, y cuyos metadatos mínimos obligatorios tomarán los valores que correspondan en función de las características propias de cada metadato y de las propiedades específicas del documento, bajo la responsabilidad del órgano que expida la copia.

- Como elemento diferenciador de las copias electrónicas, se establece que la relación entre la copia electrónica auténtica y el documento origen se reflejará en los metadatos del documento electrónico copia a través del metadato 'Identificador del documento origen'. La información de contexto a aportar por los metadatos se concreta para las copias electrónicas en el establecimiento de esta relación.

- Se referencia a la firma de las copias electrónicas auténticas, mediante alguno 
de los sistemas de firma previstos en los artículos 18 ó 19 de la Ley 11/2007, en los que se establecen los sistemas de firma electrónica por parte de las Administraciones Públicas.

Las particularidades de cada tipo de copia se desarrollan en los apartados siguientes en los que se detalla para cada una de ellas el valor a asignar al metadato mínimo obligatorio 'Estado de elaboración' al objeto de reflejar su condición de copia auténtica, homogeneizando la condición apuntada en el artículo 43 del Real Decreto 1671/2009 a todas las copias electrónicas auténticas mencionadas en la norma.

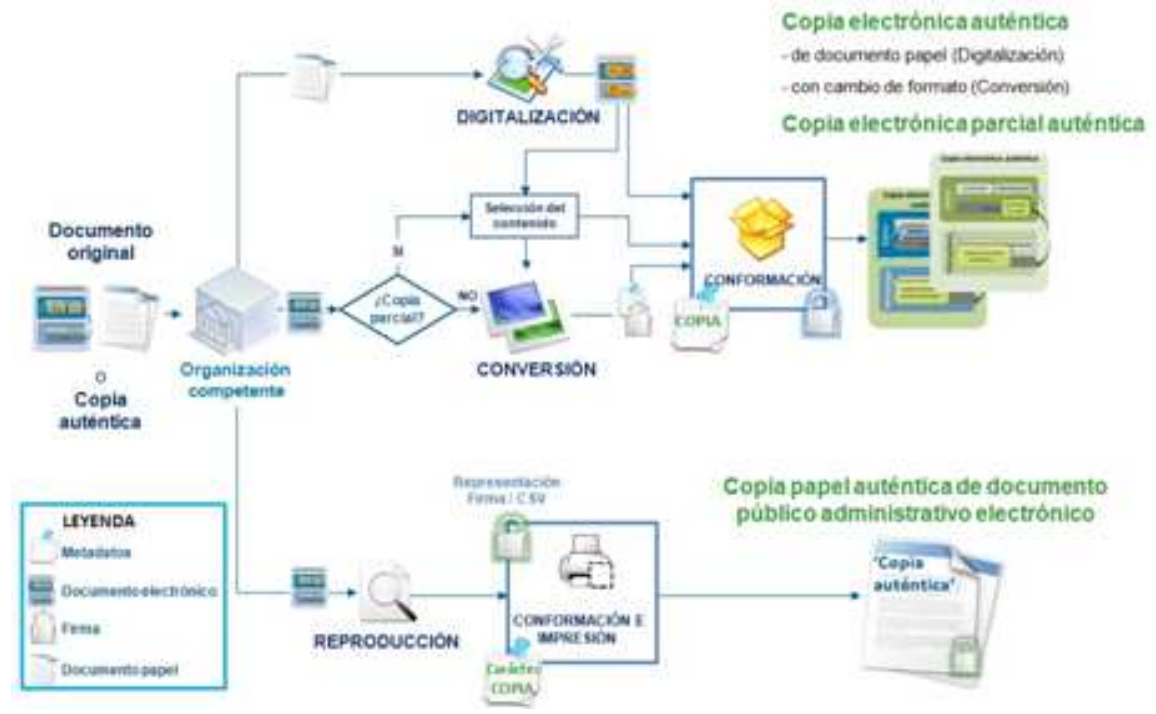

Figura 6: Procedimientos de copiado auténtico.

El apartado relativo a las copias electrónicas auténticas con cambio de formato, responde al apartado 1 del artículo 30 de la Ley 11/2007 y refleja lo establecido en el artículo 43 del Real Decreto 1671/2009. Según esto, para la obtención de este tipo de copias, se establece la aplicación de un procedimiento de conversión que responda a lo establecido en el apartado VIII de la norma para dichos procesos, con el fin de garantizar la normalización de los aspectos básicos de dicho proceso, así como la asignación del valor $<<$ Copia electrónica auténtica con cambio de formato $>>$ en el metadato mínimo obligatorio 'Estado de elaboración'.

Seguidamente se trata la obtención de las copias electrónicas auténticas de documentos papel desarrollando lo dispuesto en los apartados 2, 3 y 4 del artículo 30 de la Ley 11/2007 y reflejando las condiciones expuestas en el artículo 44 del Real Decreto 1671/2009. Para la obtención de copias electrónicas auténticas de documentos en soporte papel o en otro soporte no electrónico, susceptible de digitalización a través de medios fotoeléctricos, se establece la aplicación de una digitalización que responda a lo establecido en la Norma Técnica de Interoperabilidad de Digitalización de Documentos, en la que se definen las condiciones básicas con el fin de garantizar la normalización de los aspectos fundamentales de dicho proceso, así como la asignación del valor $<<$ Copia electrónica auténtica de documento papel $>>$ en el 
metadato mínimo obligatorio 'Estado de elaboración'.

El tratamiento de la obtención de las copias electrónicas parciales auténticas responde a una necesidad práctica frecuente en la tramitación. Atiende a lo dispuesto en el artículo 49 del Real Decreto 1671/2009 y a lo apuntado en el artículo 9 del Real Decreto 772/1999 sobre la posibilidad de obtener copias auténticas mediante extractos del contenido del documento origen que corresponda o a través de la utilización de otros métodos electrónicos que permitan mantener la confidencialidad de aquellos datos que no afecten al interesado. En este caso, se asigna el valor de $<<$ Copia electrónica parcial auténtica $>>$ en el metadato mínimo obligatorio 'Estado de elaboración'.

La obtención de copias papel auténticas de documentos públicos administrativos recoge del artículo 30.5 de la Ley 11/2007 que la autenticidad puede verificarse mediante el acceso al documento electrónico correspondiente, de acuerdo con lo establecido en la Norma Técnica de Interoperabilidad de Documento Electrónico sobre acceso a los documentos electrónicos.

Finalmente, se establecen las condiciones para la conversión entre documentos electrónicos, como respuesta a lo establecido en el artículo 23 del Real Decreto 4/2010 que se concretan en:

- Definir la conversión entre documentos electrónicos como la generación de un nuevo documento electrónico con diferente formato o versión del mismo que, como tal, cumplirá con lo establecido en la Norma Técnica de Interoperabilidad de Documento electrónico.

- Aplicar procedimientos de conversión, definidos en un marco de gestión documental según la Norma Técnica de Interoperabilidad de Política de gestión de documentos electrónicos; diseñados en atención a la conservación del contenido, contex to y estructura del documento origen e identificación de los componentes que requieran, dada su naturaleza, un tratamiento específico en la conversión, como pueden ser las imágenes que acompañan un texto; donde el formato del nuevo documento convertido atienda a los establecidos en la Norma Técnica de Interoperabilidad de Catálogo de estándares y que permita la reproducción de la información contenida en el documento original minimizando el riesgo de pérdida de información.

- Más la necesidad de contemplar adicionalmente los requisitos establecidos en los puntos tercero, cuarto y quinto de la norma cuando el documento resultado de la conversión deba ser conformado como copia auténtica. 


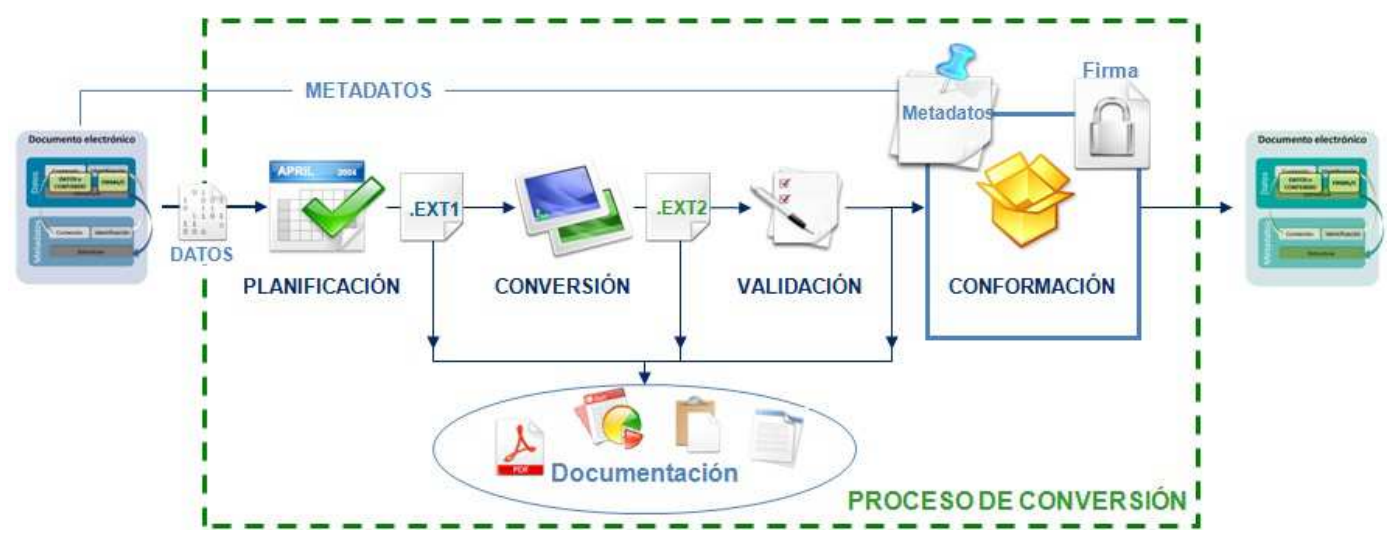

Figura 7: Procedimientos de conversión

\section{Política de gestión de documentos electrónicos}

La Norma Técnica de Interoperabilidad de Politica de gestión de documentos electrónicos ha de responder a lo previsto en el artículo 21 del Real Decreto 4/2010 sobre las condiciones para recuperación y conservación de documentos electrónicos. En dicho artículo se establece que, para garantizar la interoperabilidad en relación con la recuperación y conservación de los documentos electrónicos a lo largo de su ciclo de vida, las Administraciones públicas adoptarán las medidas organizativas y técnicas necesarias, entre las que se encuentra la definición de una política de gestión de documentos. Además, en este mismo artículo se indican otras medidas relativas a la asociación de metadatos, la conservación y recuperación de documentos electrónicos, la transferencia o el borrado de información, entre otras, así como la creación de repositorios electrónicos, complementarios y equivalentes en cuanto a su función a los archivos convencionales.

Por ello, la norma persigue establecer unas pautas comunes para homogeneizar las cuestiones más básicas de la gestión documental: los conceptos relacionados con el desarrollo de políticas de gestión de documentos electrónicos, los procesos de la gestión de documentos en el marco de la administración electrónica y los principios necesarios para el desarrollo y aplicación de políticas de gestión de documentos electrónicos por parte de todos los órganos de la Administración y Entidades de Derecho Público vinculadas o dependientes de aquélla.

A la fecha de redacción de este documento la norma se encuentra en proceso de elaboración. Cabe adelantar que contempla tratar los siguientes contenidos tentativos a la luz de la normalización, y de los referentes y buenas prácticas nacionales e internacionales aplicables a la gestión documental:

- Contenidos básicos de una política de gestión de documentos electrónicos.

- Los actores involucrados en la definición, aprobación e implantación de la política de gestión de documentos electrónicos en una organización.

- El programa de tratamiento y los procesos de gestión de documentos electrónicos. 
- La asignación de metadatos de gestión a los documentos electrónicos.

- La documentación, formación, supervisión, auditoría y actualización de la política de gestión de documentos electrónicos.

\section{Metodología}

Las Normas Técnicas de Interoperabilidad publicadas, y las que se encuentran en preparación a la fecha, se vienen elaborando con la participación de más de 200 expertos que reúnen perfiles diversos de conocimiento (tecnologías de la información, archivos, jurídico), provenientes de la Administración General del Estado, las Comunidades Autónomas, las Corporaciones Locales a través de la Federación Española de Municipios y Provincias (FEMP) y las Universidades a través de la Conferencia de Rectores de Universidades Españolas (CRUE), más la colaboración con el ámbito de la Justicia a través Esquema Judicial de Interoperabilidad y Seguridad (EJIS).

El proceso de elaboración de las normas incluye las siguientes actividades:

- Se ha investigado y analizado de forma pormenorizada los requisitos, así como los referentes y fuentes de autoridad provenientes de la normalización, las buenas prácticas de aceptación generalizada, la Unión Europea y otros países.

- Se han identificado prioridades, a la luz de la perspectiva general, de forma que el orden de elaboración ha sido: documento electrónico, expediente electrónico, digitalización de documentos, procedimientos de copiado auténtico y conversión y, seguidamente, política de gestión de documentos electrónicos.

- Se ha elaborado una documentación exhaustiva que permita a los actores comprender el alcance del problema y facilite alcanzar una comprensión común de las cuestiones, debatir y adoptar decisiones sobre alcance, principios y aspectos generales y de detalle.

- Sobre la base de lo anterior, se han redactado los correspondientes textos escuetos de carácter normativo, en los que se eluden los contenidos de naturaleza teórica o explicativa.

- Se han revisado los textos en sucesivas iteraciones para consolidar la comprensión común, consensuar los diversos aspectos, depurar y perfeccionar los detalles.

- Se han publicado los borradores en el Portal de la Administración Electrónica (29 de abril de 2011).

- Se han elevado las propuestas para aprobación formal y posterior tramitación. 
- Aprovechando el caudal de documentación se han elaborado unas guías de aplicación.

\section{Conclusiones}

Las administraciones públicas españolas vienen realizando un esfuerzo considerable en los últimos años para garantizar a los ciudadanos su derecho a relacionarse electrónicamente con ellas. La seguridad jurídica, aspecto esencial en la implantación de la administración electrónica, ha absorbido parte de ese esfuerzo, orientado al desarrollo de la Ley 11/2007 y materializado en el Real Decreto 1671/2009 de desarrollo parcial de la Ley 11/2007, y seguidamente, en los Reales Decretos 3/2010 y 4/2010 relativos a los esquemas nacionales de seguridad e interoperabilidad respectivamente, que desarrollan los principios y pautas necesarios para crear condiciones de confianza en los sistemas tecnológicos y para la cooperación entre las distintas administraciones.

En julio de 2011, se han publicado siete de las normas técnicas de interoperabilidad de la serie prevista en el Real Decreto 4/2010. En particular, el esfuerzo colectivo realizado desde finales de 2009 para la elaboración de las normas técnicas de interoperabilidad relativas al documento electrónico ha estado en la mente de todos los participantes la necesidad de concretar, de manera priorizada, con vistas a lograr resultados tangibles ceñidos a las necesidades más inmediatas de aplicación de la Ley 11/2007 y de sus desarrollos reglamentarios; de manera que, con gran generosidad por parte de unos y de otros, que a todos ellos hay que agradecer, se ha consensuado acotar alcances y limitar el desarrollo de detalles que pudieran arrastrar a una dinámica de perfeccionamiento sin fin y sin límite de tiempo, entendiendo todos, además que tiempo habrá para futuras versiones. No debe resultar difícil imaginar las diferentes perspectivas de los diversos actores a lo largo del proceso, las tensiones que ha podido haber para encontrar los puntos de equilibrio y los resultados si alguno o algunos de ellos hubieran porfiado en una visión unilateral sin sentido del interés común, cosa que también es de agradecer que no haya ocurrido.

Se ha perseguido que estas normas puedan satisfacer necesidades derivadas de la normativa aplicable y que puedan aplicarse con un esfuerzo razonable dentro de los plazos previstos para la adecuación al Esquema Nacional de Interoperabilidad. Esto ha implicado la necesidad de tomar decisiones, por ejemplo, en cuanto a la limitación de alcances, desde un planteamiento basado en mínimos en función de lo que los diversos actores pueden aceptar y aplicar, que favorezcan su implantación en un plazo razonable. Además, las bases definidas para el desarrollo de las normas persiguen proporcionar un marco inicial sobre el que evolucionar de forma gradual y atender a posibles futuras necesidades manteniendo su alineación con tendencias y estándares europeos e internacionales.

Para facilitar su comprensión y aplicación, estas normas van acompañadas de las correspondientes guías de aplicación, de un manual sobre los esquemas XSD de documento electrónico y de expediente electrónico y de una herramienta de validación de los citados esquemas XSD. Todos estos instrumentos de apoyo están disponibles en el Portal de la Administración Electrónica4. 
El trabajo continúa pues, por un lado, restan algunas normas por elaborar y, por otro lado, la aplicación práctica de las Normas Técnicas de Interoperabilidad pondrá a prueba su bondad, permitirá identificar los posibles aspectos a completar, añadir o eliminar y requerirá un esfuerzo de gobernanza para gestionar su actualización. Por otra parte, un siguiente hito importante será la publicación de las Normas Técnicas de Interoperabilidad de Política de gestión de documentos electrónicos y de Catálogo de Estándares.

\section{Agradecimientos}

La elaboración de estas normas técnicas de interoperabilidad relativas al documento electrónico ha sido posible gracias al trabajo que bajo la coordinación del Ministerio de Política Territorial y Administración Pública han realizado los Grupos de trabajo del Esquema Nacional de Interoperabilidad, con participación de expertos de la Administración General del Estado, las Comunidades Autónomas, las Corporaciones Locales a través del FEMP y las Universidades a través de la CRUE. Cabe destacar, en particular, las contribuciones de la Agencia Estatal de Administración Tributaria y del Ministerio de Cultura, el apoyo de INTECO y de su equipo técnico, $\mathrm{D}^{\mathrm{a}}$ Elena García Díez, D ${ }^{a}$ Tatiana Gutiérrez Marqués, $D^{a}$ Ana Belén Santos Pintor y D ${ }^{a}$ Nerea Urquijo Valbuena, así como de los expertos D. Joaquim Llansó de la Universidad Pública de Navarra y D. Alejandro Delgado del Ayuntamiento de Cartagena. A todos ellos les agradezco su colaboración, dedicación y apoyo.

\section{Referencias}

Ley 11/2007, de 22 de junio, de acceso electrónico de los ciudadanos a los Servicios Públicos. URL:

http://www.boe.es/boe/dias/2007/06/23/pdfs/A27150-27166.pdf

Real Decreto 1671/2009, de 6 de noviembre, por el que se desarrolla parcialmente la Ley 11/2007, de 22 de junio, de acceso electrónico de los ciudadanos a los servicios públicos. URL:

http://www.boe.es/boe/dias/2009/11/18/pdfs/BOE-A-2009-18358.pdf

Real Decreto 4/2010, de 8 de enero, por el que se regula el Esquema Nacional de Interoperabilidad en el ámbito de la Administración Electrónica. URL: http://www.boe.es/boe/dias/2010/01/29/pdfs/BOE-A-2010-1331.pdf

Real Decreto 3/2010, de 8 de enero, por el que se regula el Esquema Nacional de Seguridad en el ámbito de la Administración Electrónica. URL: http://www.boe.es/boe/dias/2010/01/29/pdfs/BOE-A-2010-1330.pdf

Boletín Oficial del Estado: sábado 30 de julio de 2011, Núm. 182. URL: http://www.boe.es/boe/dias/2011/07/30/

Resolución de 19 de julio de 2011 , de la Secretaría de Estado para la Función Pública, por la que se aprueba la Norma Técnica de Interoperabilidad de Digitalización de 
Documentos. URL:

http://www.boe.es/boe/dias/2011/07/30/pdfs/BOE-A-2011-13168.pdf

Resolución de 19 de julio de 2011 , de la Secretaría de Estado para la Función Pública, por la que se aprueba la Norma Técnica de Interoperabilidad de Documento Electrónico. URL:

http://www.boe.es/boe/dias/2011/07/30/pdfs/BOE-A-2011-13169.pdf

Resolución de 19 de julio de 2011 , de la Secretaría de Estado para la Función Pública, por la que se aprueba la Norma Técnica de Interoperabilidad de Expediente Electrónico. URL:

http://www.boe.es/boe/dias/2011/07/30/pdfs/BOE-A-2011-13170.pdf

Resolución de 19 de julio de 201 1, de la Secretaría de Estado para la Función Pública, por la que se aprueba la Norma Técnica de Interoperabilidad de Política de Firma Electrónica y de certificados de la Administración. URL:

http://www.boe.es/boe/dias/2011/07/30/pdfs/BOE-A-2011-13171.pdf

Resolución de 19 de julio de 2011 , de la Secretaría de Estado para la Función Pública, por la que se aprueba la Norma Técnica de Interoperabilidad de Procedimientos de copiado auténtico y conversión entre documentos electrónicos. URL: http://www.boe.es/boe/dias/2011/07/30/pdfs/BOE-A-2011-13172.pdf

Resolución de 19 de julio de 201 1, de la Secretaría de Estado para la Función Pública, por la que se aprueba la Norma Técnica de Interoperabilidad de requisitos de conexión a la red de comunicaciones de las Administraciones Públicas españolas.

URL:

http://www.boe.es/boe/dias/2011/07/30/pdfs/BOE-A-2011-13173.pdf

Resolución de 19 de julio de 2011 , de la Secretaría de Estado para la Función Pública, por la que se aprueba la Norma Técnica de Interoperabilidad de Modelo de Datos para el Intercambio de asientos entre las entidades registrales. URL: http://www.boe.es/boe/dias/2011/07/30/pdfs/BOE-A-2011-13174.pdf

Decisión de la Comisión 2011/130/EU, de 25 de febrero de 2011, por la que se establecen los requisitos mínimos para el tratamiento transfronterizo de los documentos firmados electrónicamente por las autoridades competentes en virtud de la Directiva 2006/123/CE del Parlamento Europeo y del Consejo relativa a los servicios en el mercado interior. URL:

http://www.boe.es/doue/2011/053/L00066-00072.pdf

Resumen ejecutivo del informe presentado al Consejo de Ministros, de 16 de septiembre de 2011 sobre la situación de la Administración Electrónica en la Administración General del Estado, septiembre 2011. URL:

http://administracionelectronica.gob.es/?_nfpb=true\&_pageLabel=P3401115701310 $558814745 \&$ langPae $=$ es\&detalleLista $=$ PAE_13167780323707773 
Comunicación $\operatorname{COM}(2010)$ 744 final Comunicación de la Comisión "Hacia la interoperabilidad para los servicios públicos europeos". URL:

http://eur-

lex.europa.eu/LexUriServ/LexUriServ.do?uri=COM:2010:0744:FIN:ES:PDF

Guía de aplicación de Digitalización de Documentos. URL:

http://administracionelectronica.gob.es/?_nfpb=true\&_pageLabel=P6021590127420 3521811 \&langPae $=$ es

Guía de aplicación de Documento Electrónico. URL:

http://administracionelectronica.gob.es/?_nfpb=true\&_pageLabel=P6021590127420 3521811 \&langPae $=$ es

Guía de aplicación de Expediente Electrónico. URL:

http://administracionelectronica.gob.es/?_nfpb=true\&_pageLabel=P6021590127420 $3521811 \&$ langPae $=$ es

Guía de aplicación de Política de firma electrónica y de certificados. URL: http://administracionelectronica.gob.es/?_nfpb=true\&_pageLabel=P6021590127420 3521811 \&langPae $=$ es

Guía de aplicación de Procedimientos de copiado auténtica y conversión. URL: http://administracionelectronica.gob.es/?_nfpb=true\&_pageLabel=P6021590127420 $3521811 \&$ langPae $=$ es

Guía de aplicación de Requisitos de conexión a la Red de comunicaciones de las Administraciones Públicas españolas. URL:

http://administracionelectronica.gob.es/?_nfpb=true\&_pageLabel=P6021590127420 3521811 \&langPae $=$ es

Manual de usuario de esquemas XML para intercambio de documentos electrónicos y expedientes electrónicos. URL:

http://administracionelectronica.gob.es/?_nfpb=true\&_pageLabel=P6021590127420 $3521811 \&$ langPae $=$ es

\section{Notas}

1. Decisión de la Comisión 2011/130/EU, de 25 de febrero de 2011, por la que se establecen los requisitos mínimos para el tratamiento transfronterizo de los documentos firmados electrónicamente por las autoridades competentes en virtud de la Directiva 2006/123/CE del Parlamento Europeo y del Consejo relativa a los servicios en el mercado interior.

2. ORDEN PRE/2971/2007, de 5 de octubre, sobre la expedición de facturas por medios electrónicos cuando el destinatario de las mismas sea la Administración General del Estado u organismos públicos vinculados o dependientes de aquélla y sobre la presentación ante la Administración General del Estado o sus organismos públicos vinculados o dependientes de facturas expedidas entre particulares. 
MEI, II, Vol. 3, nº 4, pág. 149

3. Real Decreto 772/1999, de 7 de mayo, por el que se regula la presentación de solicitudes, escritos y comunicaciones ante la Administración General del Estado, la expedición de copias de documentos y devolución de originales y el régimen de las oficinas de registro.

4. http://administracionelectronica.gob.es 